\title{
COEVALUATION AND GRADING OF ENGINEERING STUDENTS IN VENEZUELA USING AHP
}

\author{
Aidaelena Smith-Perera* \\ Universidad Metropolitana \\ Caracas, Venezuela \\ E-mail: asmith@unimet.edu.ve \\ Carmen Lucía Rojas-Lima \\ Universidad Metropolitana \\ Caracas, Venezuela \\ E-mail: crojas@unimet.edu.ve
}

\begin{abstract}
Knowledge transfer among peers can favor learning. On the other hand, coevaluation, as understood in this investigation, implies the evaluation of peers' assessment when transferring knowledge developed by them. Additionally, knowledge transfer and coevaluation contribute in the development of certain competences in assignments that comprise: 1) sharing the results with the whole class, 2) analysis, 3) commitment and 4) responsibility. However, objectivity when assessing peer performance is an issue and a concern, basically due to the fact that, although peers are recipients of the information being shared, they do not get involved in the evaluation as stakeholders. As part of the evolution of learning, students need to evolve to recognize their capability to evaluate, since for some, peer evaluation can be intimidating. In this investigation, the use of AHP have been applied in three courses and to a total of 103 students in engineering at Universidad Metropolitana, particularly those almost at the end of their programs to investigate the feasibility of getting a more objective coevaluation of students by their peers. Methodology, results and final grading are discussed and next steps are presented. There is still much to do in this area to get objectivity from evaluation since high inconsistencies were found and final grading allocation has not yet been defined. However, AHP is still considered the best technique to address this problem.
\end{abstract}

Keywords: Co-evaluation, AHP, peer performance

\section{Introduction}

Universidad Metropolitana (Unimet) is a private university in Caracas, Venezuela with 5.500 students among undergraduate and graduate. Currently Unimet has four faculties and 15 undergraduate programs that include Engineering Faculty with six (6) undergraduate programs in Engineering. This investigation is proposed to take place in courses that are normally taken almost at the end of their 12-quarter programs, specifically for Industrial engineering. Those courses normally host between 35 and 40 students. Each student decides each quarter which courses he/she registers for.

The investigation comprises three related areas: project-based learning, assessment of knowledge transfer among classmates performed by peers (coevaluation) and the application of AHP as a technique to obtain more objective evaluation results.

\footnotetext{
${ }^{*}$ Corresponding author
} 
Teachers from different courses in engineering at Unimet have identified the fact that students do not get interested in participating when peers share knowledge acquire by themselves, particularly when sharing results of projects.

Teachers in the Faculty of Engineering in Unimet have studied the effect of project-based learning and assessment of peer performance when sharing their self-acquire knowledge since 2009. It is after getting some results on coevaluation when AHP is proposed to get more balanced evaluation. The challenge is to establish a methodology that can be applied in different courses and is trustable and guarantee objective results.

Due to the fact that all students not necessarily attend their course at the same time, evaluation of peer assessment has to be gotten at once, with no time to review and improve objectivity and once the quarter is over, students are not longer available to the teacher. The methodology has to be robust, yet easy to implement and process.

Project grading is still under investigation so it is not the main part of the methodology to be proposed.

\section{Coevaluation and it significance in learning}

In this investigation, as stated before, the authors combine coevaluation, self-learning and share of knowledge with peers as a combination that can result in better individual performance and more permanent learning.

Self or project-based learning is part of the changes occurring in education to improve learning in which learning is focused on the student rather than the teacher, according to Gessa-Perera (2010).

Alvarez (2008) found in a co-assessment experience that it may be used as an effective procedure to learning experience improvement. Coevaluation contributes in learning, according to experiences in Unimet, in the context of students sharing results of short investigations with their peers, since having to perform coevaluation forces students to stay focused. The drawback of handing out the responsibility of sharing knowledge among peers, especially when topics are new, is the higher possibility of conceptual mistakes or presentation of incorrect information so teacher intervention is required at a point in the process to guarantee that there such misinformation presented in front of the class.

Gessa-Perera (2010) and Ozogul and Sullivan (2007) review coevaluation and ways of performing coevaluation as a way to impact on learning both for students and evaluators/teachers. Ozogul and Sullivan (2007) stated that student's attitude toward evaluation favors teachers over peers

Lavy and Yadin (2010) stated that engagement achieved by peer evaluation provide the exposure to ideas of others, promotes critical thinking and raises students' levels of understanding.

\section{Coevaluation and MCDA}

Muda et al (2012) propose a ranking method of the factors that lecturers must take care of in order to improve their effective teaching. In this study students establish the ranking to improve their lecturers teaching strategies. 
Başbay and Ateş (2009) discussed the importance of project-based learning in one of the goal of developing in students the ability to find effective solutions to problems in real life. In this investigation Başbay and Ateş compare as well self-evaluation and teacher evaluation method in the learning process.

In the area of decision making and student performance evaluation, Gokmen et al (2010) compare classical evaluation methodology based on final test and grading versus a new performance evaluation method using fuzzy logic, which results more complicate though more flexible.

Some other authors (Jang et al (2009), Aziz and Yatim(2012) and Özgüngör(2009) ) study students' perception on learning evaluating the role of teachers on that and the effectiveness evaluation in learning. Authors try to establish the relationship between evaluation and teacher's ability to promote the effective learning.

\section{Methodology}

As discussed previously, coevaluation understood as a strategy to get better results in learning, comprises a whole methodology that includes student participation in front of his/her classmates and the assessment itself, based on AHP. As far as this investigation covers, students investigate a new subject, prepares themselves for a forum. Forum takes place in one session and classmates evaluate the performance, with different criteria, using AHP. Teacher participation in performance evaluation is discussed later. Students are always grouped to prepare and do the forum. Evaluation is always done on the whole group either individually or on the group. The original methodology is presented in figure 1.

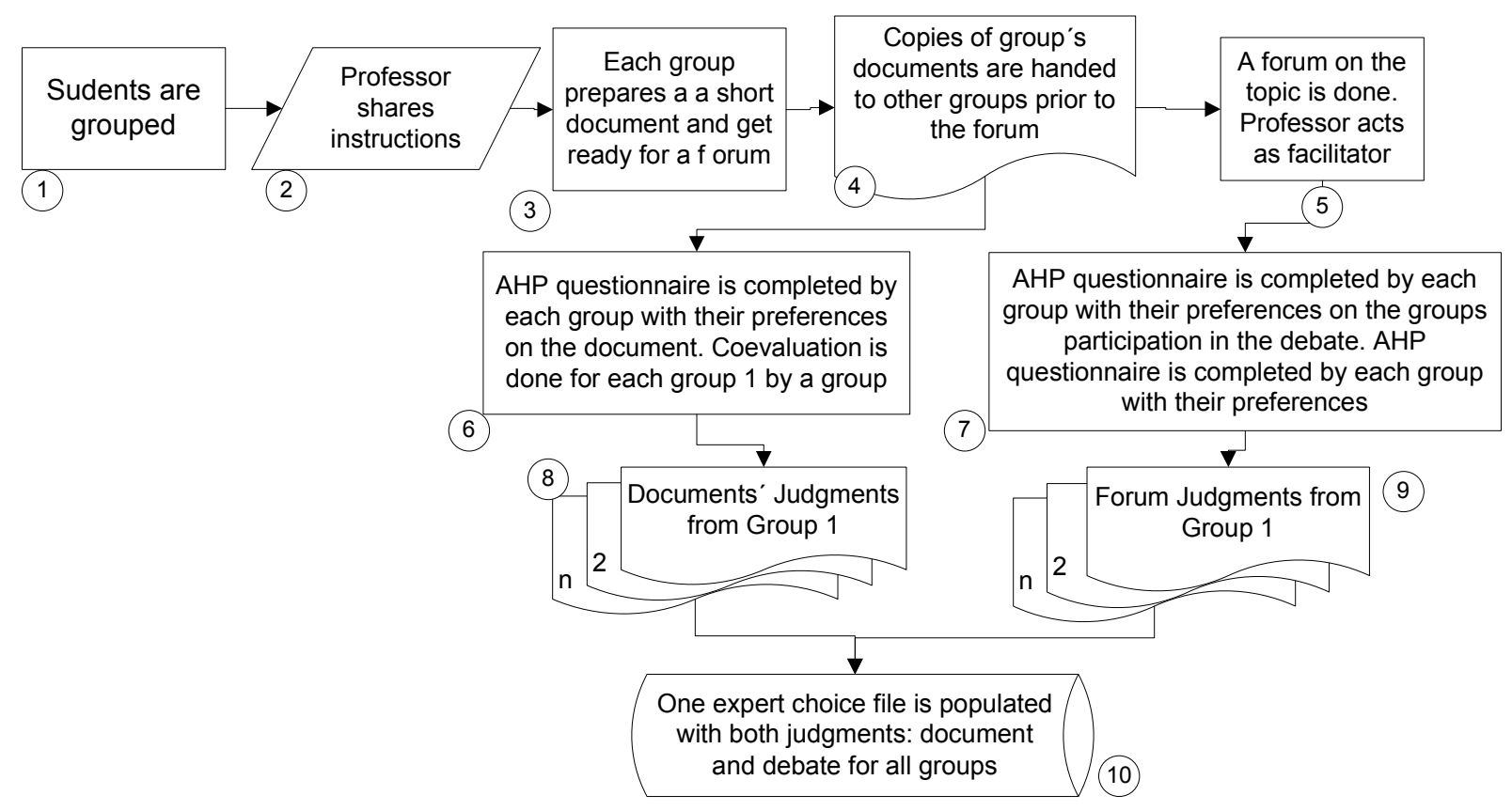

Figure 1. Methodology used for coevaluation in Unimet

In this methodology assessment is evaluated in two aspects: first, the document which is given to the class and second, the participation of each of the groups in the forum. Document is evaluated in three aspects: 
1) information included in it, 2) quality of the document and 3) how useful classmates considered it in their professional instruction, as shown in figure 2.

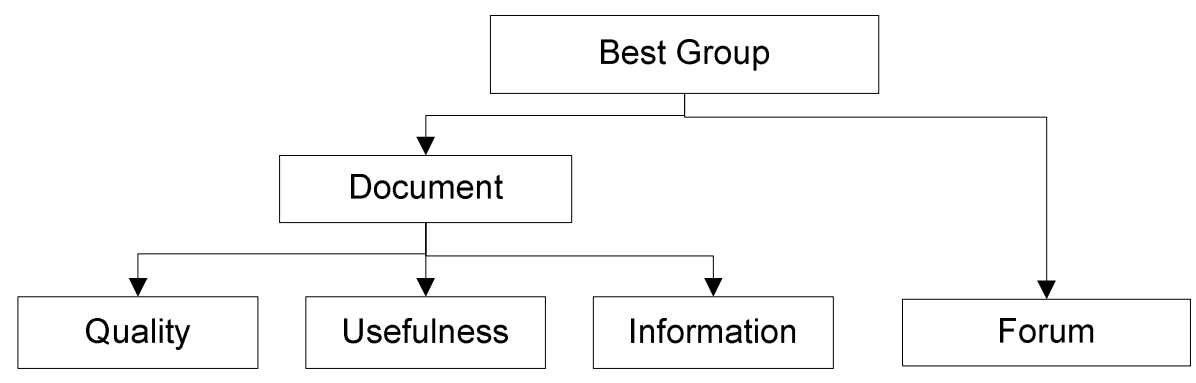

Figure 2. AHP model for coevaluation

Weight of each criterion is calculated by paired-comparisons by teacher. Students do not participate in the assignment of weight to criteria.

After evaluating results from two different courses in 2009 and 2012, both from almost last quarter, some changes were done in the methodology.

The changes performed in the methodology include various aspects:

- Criteria were re-evaluated and resized to eliminate those that should responsibility of the teacher, related to following instructions such as usefulness and information.

- Instead of group evaluation, individual evaluation is proposed and tested

- Instead of document and forum, a presentation is asked to be prepared by each group and presented in front of the class

- Due to the amount of participants more than one Expert Choice® file is populated with data

Results in application of both methodologies are discussed later.

\section{Application of methodology}

Original methodology was applied on a course of 33 students. Students were divided into seven groups of 4 to 5 students each. All groups had 4 weeks for preparation according to instructions given by the teacher. Forum was scheduled for fifth week. Each group was asked to prepare a one-page long handwritten document with different subjects and 8 copies of the document were requested ( 1 for the teacher and one for each group, including them).

Pair-comparison questionnaires were two: one for the document and another for the forum.

The first pair-comparison questionnaire (document) was handed after distribution of the documents among groups. Each group completed one questionnaire with judgments decided by consensus. Second questionnaire was handed (one per group) when the forum was over.

It all took place in one session. Priorities and inconsistencies are shown in tables 1 and 2.

As we can observe in results, inconsistencies for groups 2 and 5 are extremely high or judgments are incomplete. Groups 4, 6 and 7 have inconsistency partially high for some of the criteria. 
Table 1. Resulting priorities when applying original methodology

\begin{tabular}{|c|c|}
\hline Group & Priorities \\
\hline 1 & 0,167 \\
\hline 2 & 0,169 \\
\hline 3 & 0,062 \\
\hline 4 & 0,14 \\
\hline 5 & 0,083 \\
\hline 6 & 0,179 \\
\hline 7 & 0,2 \\
\hline
\end{tabular}

Table 2. Calculated inconsistencies for original methodology

\begin{tabular}{|l|l|c|c|c|c|c|c|c|}
\cline { 3 - 9 } \multicolumn{2}{l|}{} & Group 1 & Group 2 & Group 3 & Group 4 & Group 5 & Group 6 & Group 7 \\
\hline \multirow{3}{*}{ Document } & Quality & $10 \%$ & $16 \%$ & $9 \%$ & $8 \%$ & $40 \%$ & $16 \%$ & $14 \%$ \\
\cline { 2 - 9 } & Information & $11 \%$ & $101 \%$ & $13 \%$ & $43 \%$ & $18 \%$ & $12 \%$ & $14 \%$ \\
\cline { 2 - 9 } & Usefulness & $1 \%$ & $37 \%$ & $19 \%$ & $11 \%$ & $84 \%$ & $9 \%$ & $7 \%$ \\
\hline Forum & $10 \%$ & $69 \%$ & $1 \%$ & $8 \%$ & Incomplete & $50 \%$ & $44 \%$ \\
\hline
\end{tabular}

The challenge when using AHP on coevaluation with the students in Unimet is that there is no possibility of going back to participants to review and get consistent judgments, because of limited time and the impact on giving impressions and preferences on their mates' assessment on one activity is lost after leaving the classroom. Coevaluation has to be done the best possible way as soon as the activity is over. Another challenge is that once results are obtained, the quarter is over and the group of students changes.

Having inconsistencies as high as those shown on table 2 for some groups and some criteria, a review of the criteria was done as part of the definition of a steady methodology that can be used and that would guarantee reliable results for coevaluation in engineering.

One of the feedbacks from students when evaluating results from original AHP model was that the questionnaire was too long, some of the questions were "not logical", and that it was very challenging to get an agreement among students of their groups when comparing the rest of the groups in a limited time with in the duration of the session.

Changes on methodology were made as stated in previous chapter and the new AHP model was built and corresponding questionnaires were formulated. Also, instead of a forum presentations were asked to be prepared. An additional document was not required.

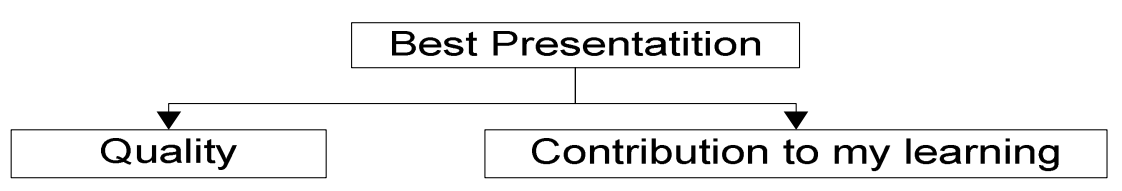

Figure 3. New AHP model for coevaluation in Unimet 
There were 36 students registered in the course. They were divided into 12 groups that prepared in 5 minutes presentation in two sessions. Each student was asked separately to complete a questionnaire with pair comparisons on presentations. Five of the students had incomplete questionnaires because they did not attend second session. For processing purposes, the 36 questionnaires were divided into 4 Expert Choice ${ }^{\circledR}$ file. Resulting priorities from each file were averaged to get final results. Results are shown in tables 3 and 4 .

Table 3. Inconsistencies on new methodology

\begin{tabular}{|c|c|c|c|c|c|c|c|c|c|c|c|}
\hline \multicolumn{3}{|c|}{ File 1} & \multicolumn{3}{|c|}{ File 2} & \multicolumn{3}{|c|}{ File 3} & \multicolumn{3}{|c|}{ File 4} \\
\hline $\begin{array}{c}\text { Partici } \\
\text { pant }\end{array}$ & $\begin{array}{c}\text { Qualit } \\
y\end{array}$ & $\begin{array}{c}\text { Contrib } \\
\text { ution }\end{array}$ & $\begin{array}{c}\text { Partici } \\
\text { pant }\end{array}$ & $\begin{array}{c}\text { Qualit } \\
y\end{array}$ & $\begin{array}{c}\text { Contrib } \\
\text { ution }\end{array}$ & $\begin{array}{l}\text { Partici } \\
\text { pant }\end{array}$ & $\begin{array}{c}\text { Qualit } \\
y\end{array}$ & $\begin{array}{c}\text { Contrib } \\
\text { ution }\end{array}$ & $\begin{array}{c}\text { Particip } \\
\text { ant }\end{array}$ & Quality & $\begin{array}{c}\text { Contrib } \\
\text { ution }\end{array}$ \\
\hline 1 & $\mathrm{~N} / \mathrm{A}$ & $\mathrm{N} / \mathrm{A}$ & 11 & $14 \%$ & $17 \%$ & 21 & $25 \%$ & $29 \%$ & 31 & $10 \%$ & $12 \%$ \\
\hline 2 & $\mathrm{~N} / \mathrm{A}$ & $\mathrm{N} / \mathrm{A}$ & 12 & $9 \%$ & $9 \%$ & 22 & $24 \%$ & $24 \%$ & 32 & $19 \%$ & $19 \%$ \\
\hline 3 & N/A & N/A & 13 & $20 \%$ & $21 \%$ & 23 & $10 \%$ & $14 \%$ & 33 & $20 \%$ & $24 \%$ \\
\hline 4 & $14 \%$ & $26 \%$ & 14 & $8 \%$ & $9 \%$ & 24 & $14 \%$ & $10 \%$ & 34 & $22 \%$ & $19 \%$ \\
\hline 5 & $\mathrm{~N} / \mathrm{A}$ & $\mathrm{N} / \mathrm{A}$ & 15 & $11 \%$ & $6 \%$ & 25 & $4 \%$ & $4 \%$ & 35 & $10 \%$ & $13 \%$ \\
\hline 6 & $41 \%$ & $32 \%$ & 16 & $7 \%$ & $13 \%$ & 26 & $8 \%$ & $4 \%$ & 36 & $27 \%$ & $35 \%$ \\
\hline 7 & 29 & $32 \%$ & 17 & $12 \%$ & $6 \%$ & 27 & $25 \%$ & $27 \%$ & & & \\
\hline 8 & 12 & $11 \%$ & 18 & $12 \%$ & $18 \%$ & 28 & $9 \%$ & $11 \%$ & & & \\
\hline 9 & 17 & $17 \%$ & 19 & $19 \%$ & $12 \%$ & 29 & $16 \%$ & $15 \%$ & & & \\
\hline 10 & N/A & N/A & 20 & $10 \%$ & $12 \%$ & 30 & $22 \%$ & $19 \%$ & & & \\
\hline
\end{tabular}

As we can observe, inconsistencies are lower than the ones from previous case. Students were more satisfied even though questionnaires were longer since there were more groups than previous case.

All participants with inconsistencies lower than $30 \%$ were included in the calculation. Thus, only participants, 6 and 36, were eliminated.

On the other hand 14 students were sufficiently consistent.

Satisfaction was consulted with student after the results were calculated. Feedback obtained included discomfort with results, especially by some member of the last preferred groups, who complained about having the peers performed the assessment and lack of teacher participation, but no about AHP or the questionnaires, arguing that peers could be "irresponsibly" when performing the coevaluation.

Table 4 shows combined preferences and final grades which were normalized by 20 to get final grades for presentations. Each group member got the same grade as the group's grade. The most preferred group got 20 points (highest grade possible in Unimet) as the grade for presentations, while the least preferred groups got 11,1 points. This presentation is worth $10 \%$ of the final grade.

The grades calculated by normalization and shown in table 4 are still under revision. Normalization is one of the ways of calculating final grades, but different criteria are under revision. However, they all considered the requirement of respecting priorities obtained with AHP. 
Table 4. Global Priorities and final grades for presentations

\begin{tabular}{|c|c|c|}
\hline \multicolumn{2}{|c|}{ Globales Priorities } & \multicolumn{1}{c}{} \\
\cline { 1 - 2 } Group & Priority (\%) & Final grade \\
\hline 5 & 11,28 & 20 \\
\hline 10 & 9,85 & 17,5 \\
\hline 8 & 9,15 & 16,2 \\
\hline 7 & 9,13 & 16,2 \\
\hline 12 & 8,75 & 15,5 \\
\hline 4 & 8,70 & 15,4 \\
\hline 6 & 8,03 & 14,2 \\
\hline 2 & 7,33 & 13,0 \\
\hline 9 & 7,30 & 12,9 \\
\hline 1 & 7,20 & 12,8 \\
\hline 11 & 6,98 & 12,4 \\
\hline 3 & 6,25 & 11,1 \\
\hline
\end{tabular}

Some teachers prefer having a high and low limits, calculated using the shape of the curve represented by priorities, like the one in figure 4. Results are ordered from most preferred to least preferred groups. Group number is shown on the horizontal axis.

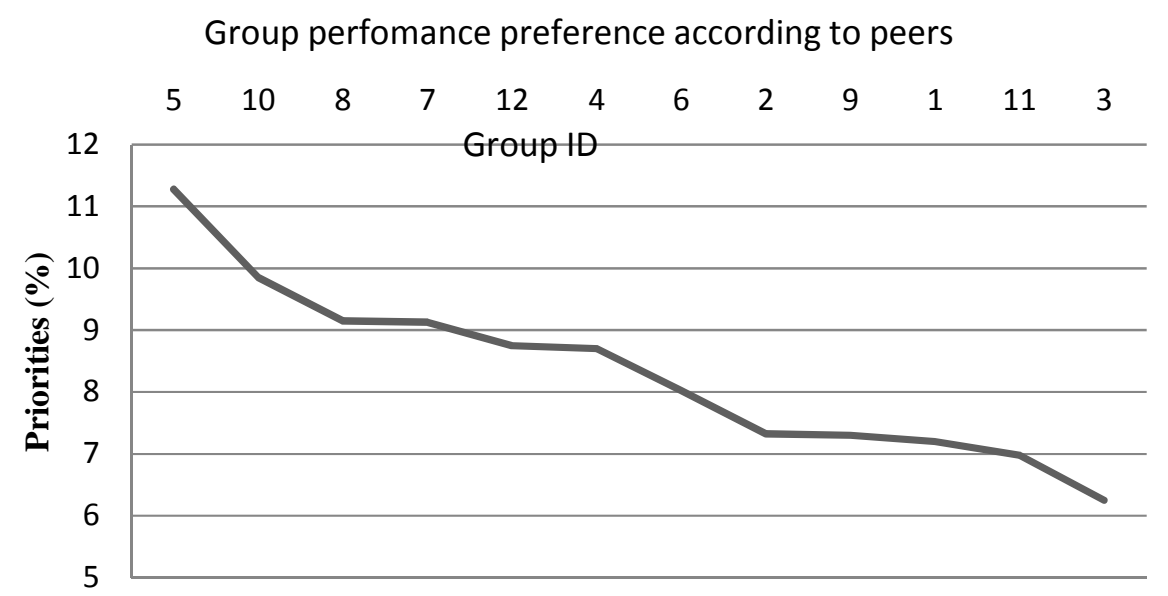

Figure 4. Shape of curve priorities ordered

\section{Conclusions}

AHP allows teachers to structure a systematic way of performing peer assessment and at the same time allows students to judge their peers perform when sharing information on a specific topic with improved objectivity 
Although in the last evaluation inconsistencies are higher than standards, results are better considering that judgements are obtained in just one attempt, with no correction.

After several experiences in the area, facilitators must be aware that robustness of the methodology must consider the fact that participators cannot be readdressed to improve inconsistencies due to the dynamics of the quarter itself and the time frame available to each evaluation from teachers and students.

Methodology to prioritize student performance using coevaluation has been becoming more reliable but grading is still under revision and improvements should pursue in the following aspects: 1) final grading calculation that is accepted among teachers in engineering at Unimet, 2) teacher participation in the assessment and 3) determination of acceptable inconsistency limit to include/exclude judgments in calculation

\section{REFERENCES}

Alvarez, I. (2008). La coevaluación como alternativa para mejorar la calidad del aprendizaje de los estudiantes universitarios: valoración de una experiencia. Revista Interuniversitaria de Formación de Profesorado, 22 (3), 127-140.

Aziz, A., Yusof, K., Yatim, J.(2012).Evaluation on the effectiveness of learning outcomes form students' perspectives. Procedia-Social and behavioral Sciences, 56, 22-30.

Başbay, M., Ateş, A.(2009). The reflections of student teachers on project based learning and investigating self evaluation versus teacher evaluation. Procedia-Social and behavioral Sciences, 59, $535-540$.

Gessa Perera, A. (2011). Co-assesment as a complementary alternative to learning assessment. Analysis and reflection in university classroom. Revista de Educación, 354, 749-764.

Gokmen, G., Çetin T., Tektaş, M., Onat, N., Kocyigit, G., Tektaş, N.(2010).Evaluation of student performance in laboratory application using fuzzy logic. Procedia-Social and behavioral Sciences, 2, 902-909.

Jang, S., Guan S., Hsieh, H. (2009). Developing an instrument for assessing college student's perception of teachers' pedagogical content knowledge. Procedia-Social and behavioral Sciences, 1, 596-606.

Kenna, R., Berche, B. (2011). Normalization of peer-evaluation measures of group research quality across academic disciplines. Research evaluation, June, 107-116.

Lavy, I., Yadin, A. (2010). Team based peer review as a form of formative assessment - The case of a system analysis and design workshop. Journal of Information Systems Education, 21(1), 85-98

Muda, N., Banu, H., Majid, N., Anuar, K. \& Ismail, W.R. (2012). Students perspectives on lecturer characteristic for effective teaching. Procedia-Social and behavioral Sciences, 59, 535-540.

Özgüngör, N. (2009). The relationships between students' evaluations of teaching behaviors and self efficacy beliefs. Procedia-Social and behavioral Sciences, 1, 2687-2691 
A. Smith, C. Rojas/ Coevaluation and grading using AHP

Ozogul, G., Sullivan, H. (2009). Students performance and attitudes under formative evaluation by teacher, self and peer evaluators. Education Tech Research Dev, 57, 393-410 